\title{
EFFECT OF PROCESS PARAMETERS ON HARDNESS, DEPTH OF HEAT AFFECTED ZONE AND MICRO STRUCTURE OF WELDMENT IN MIG WELDING
}

\author{
Subrata Saha ${ }^{1 *}$, Naureen Binte Shahjahan ${ }^{2}$, Naseem Ahmed ${ }^{3}$ \\ ${ }^{1}$ Mechanical Technology, Kushtia Polytechnic Institute, Kushtia-7000, Bangladesh \\ ${ }^{2}$ South Dakota State University, USA \\ ${ }^{3}$ Department of Mechanical Engineering, Khulna University of Engineering and Technology, Khulna-9203 \\ "Corresponding e-mail : subrata2011new@gmail.com
}

\begin{abstract}
Electrode wire diameter, welding current, electrode wire feed rate, arc length are influential process parameters for hardness, depth of heat affected zone and microstructure of weldment in case of MIG welding process. In this work, the effect of these process parameters on weldment characteristics had been studied. Experiments were conducted using bead-on surface of medium carbon steel plate in a semi-automatic MIG welding machine. Hardness, depth of heat affected zone and microstructure of weldment were examined. An artificial neural network (ANN) based modeling of the experiments had been successfully done to realize the patterns of results obtained from the experiments. It had been observed that the microstructures obtained in these weldments were distinctly different from that of the base metal. Microstructures, hardness and depth of heat affected zone of weldment depends on the process parameters. ANN model shows good agreement with the experimental results in case of hardness and depth of heat affected zone of weldment.
\end{abstract}

Keywords: $M I G$ welding, electrode, feed rate, hardness, microstructure.

\section{INTRODUCTION}

Weld metal hardness, depth of heat affected zone and microstructure of weldment are extremely important for structural consideration in welding. These are very much influential in case of welding method, cooling rate, grain structure, structural integrity, strength and rusting probability of weldment. The process parameters like welding current, voltage, electrode wire materials, diameter and feed rate, arc length, cooling process are important and influential. The proper control of these process parameters and the characteristics give positive and accurate result ${ }^{1}$.

In this work the major process parameters were welding current, electrode wire diameter and feed rate and cooling process. To measure the weldment characteristics hardness, depth of heat affected zone (HAZ) and microstructure of weld metal had been considered. Metal inert gas (MIG) welding process with automatic or robotic system in various industries is a demanding welding process now-a-days and this process is being used with increasing rate of applications. Due to these reasons, MIG welding process had been chosen for this work.

In metallurgical aspect, it is obvious that to obtain coalescence between two metals, there must be sufficient proximity and activity between the atoms of the pieces being joined to cause the formation of common metallic crystals. The ideal metallurgical bond for which there would be no noticeable or detectable joint require (i) perfectly smooth, flat or matching surfaces, (ii) clean surfaces free from oxides, absorbed gases, grease and other contaminants, (iii) metals with no internal impurities, (iv) Metals with single crystals with identical crystallographic structure and orientation.

The metallurgical structure quality of both the weld and adjacent material can be affected by the heating and cooling cycle of the welding process. The elements exert their influence on the microstructures and physical properties across the welded joint are

(a) by strengthening of ferrite in the solid solution

(b) by formation of carbides

(c) by formation of inter metallic compounds

(d) by controlling the grain size

(e) by raising and lowering the transition temperature

(f) by varying the gas/gas mixtures combinations used, etc. ${ }^{2,3}$.

Welding upsets the ferrite-austenite micro structural balance in the weld metal and in the high temperature heat affected zone. Microstructural change affects the hardness of the weldment also.

\section{EXPERIMENTAL PROCEDURES}

To investigate the weldment characteristics like hardness, depth of heat affected zone (HAZ) and microstructure; beads were deposited on mild steel flat plates using mild steel electrodes. Number of samples taken was 40 and each sample size was $150 \mathrm{~mm} \times 75 \mathrm{~mm} \times 12 \mathrm{~mm}$. The Base metal was with $0.20 \% \mathrm{C}, 0.45 \% \mathrm{Mn}, 0.03 \% \mathrm{P}, 0.04 \% \mathrm{~S}$. A semiautomatic preset feed and current based MIG welding machine was used to deposit beads on plates. The machine had the capability to vary the electrode wire feed rate, electrode wire diameter and current. The electrode wires feed rates used for experiments were 4600 and $5600 \mathrm{~mm} / \mathrm{min}$. Electrode wire with diameters 0.8 and $1.0 \mathrm{~mm}$ were used. After 
completing the welding the weldments were cooled into normal atmosphere without using any extra cooling arrangement.

To study the predetermined characteristics, each bead was sectioned transversely at the middle of the bead. To get the microstructure and the depth of heat affected zone, these sectioned beads were then grinded, filed and polished with 0, 2, 3 grade emery paper and polishing machine and then etched with $5 \%$ nitric acid solution (Nital). To measure the depth of HAZ each sample was placed under toolmaker's microscope (least count $0.001 \mathrm{~mm}$ ). Then the metal surface was placed under a metallurgical microscope and some photographs of selected samples were taken with 50X magnification and shown in Figs. 5 to 11 as the morphological features of austenite and ferrite. Hardness number of HAZ of every sample had been measured by using a Rockwell Hardness Testing Machine on $\mathrm{C}$ scale. And the values obtained are shown in Table 1. The values of depth of HAZ and hardness number obtained by these ways were used further for training through an Artificial Neural Network (ANN).

During welding the following parameters were kept same throughout the experiment: welding speed around $140 \mathrm{~mm} / \mathrm{min}$, arc length around $3 \mathrm{~mm}$, carbon dioxide gas $\left(\mathrm{CO}_{2}\right)$ used as inert gas, gap between nozzle and plate was maintained in the range of 5-7 $\mathrm{mm}$, electrode angle was in the range of $65^{\circ}-75^{\circ}$ and straight polarity was used.

\section{RESULTS}

Table 1 shows process parameters, experimental values, values obtained through artificial neural network (ANN) of depth of HAZ and hardness of weldment and percentage of error between experimental and ANN values.

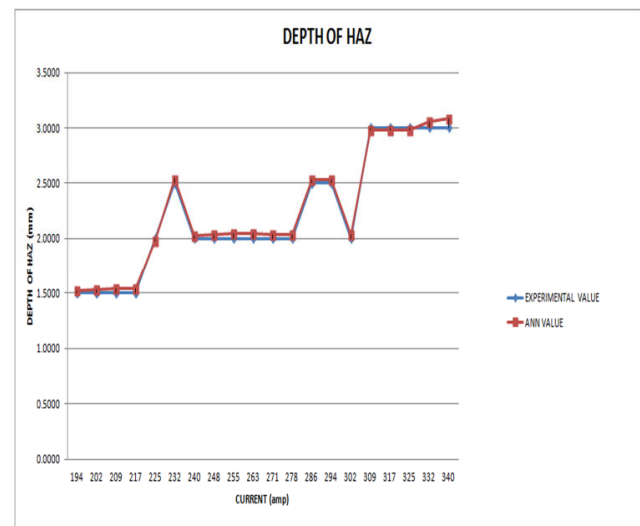

Figure 1. Depth of HAZ for electrode wire diameter $0.8 \mathrm{~mm}$.

The results of the investigation conducted on the weldment characteristics of mild steel work pieces welded with mild steel electrodes are shown in Figs. 1-4. Photographs of microstructures of base metal and selected weld metals are shown in Figs. 5-11.

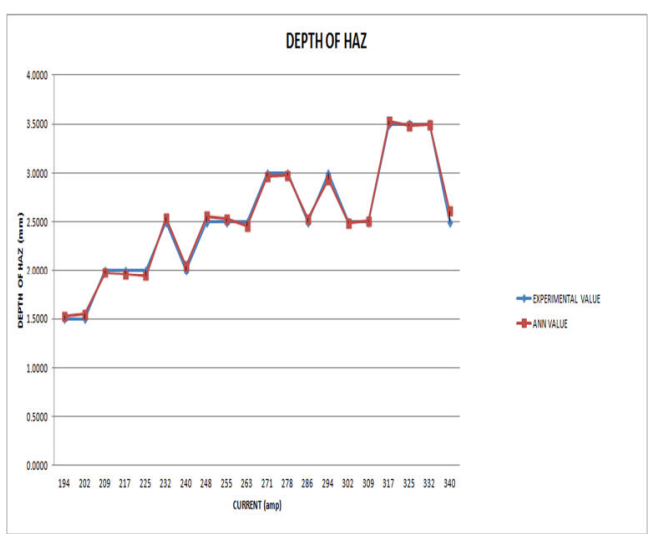

Figure 2. Depth of HAZ for electrode wire diameter $1.0 \mathrm{~mm}$.

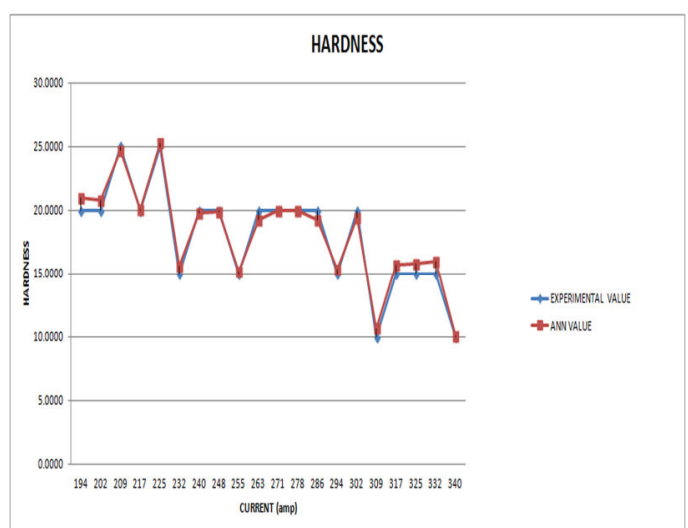

Figure 3. Hardness of weldment for electrode wire diameter $0.8 \mathrm{~mm}$.

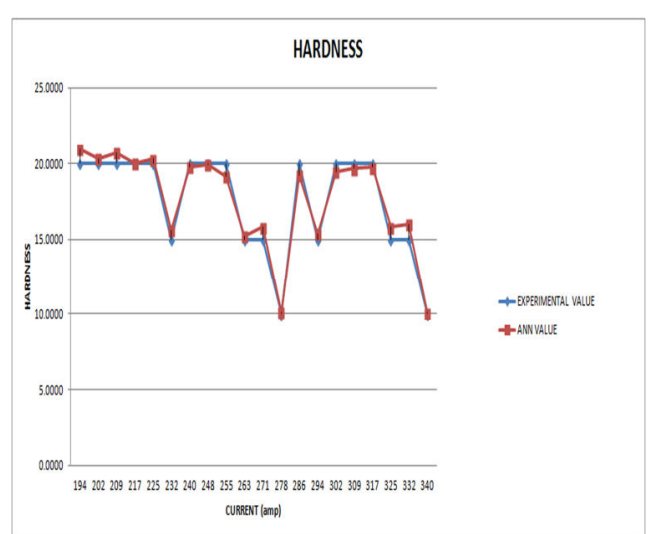

Figure 4. Hardness of weldment for electrode wire diameter $1.0 \mathrm{~mm}$.

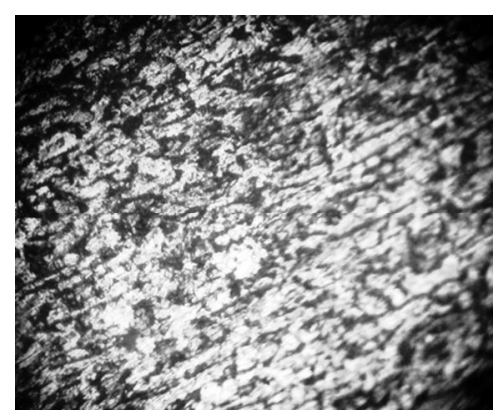

Figure 5. Microstructure of base metal. 
Table 1. Process parameters, depth of heat affected zone and weldment hardness with percentage of error.

\begin{tabular}{|c|c|c|c|c|c|c|c|c|c|}
\hline \multirow{2}{*}{$\begin{array}{c}\text { Sample } \\
\text { Serial } \\
\text { No. }\end{array}$} & \multicolumn{3}{|c|}{ Process Parameters } & \multicolumn{3}{|c|}{ Depth of HAZ (mm) } & \multicolumn{3}{|c|}{ Hardness } \\
\hline & $\begin{array}{c}\text { Wire } \\
\text { Dia } \\
(\mathrm{mm})\end{array}$ & $\begin{array}{c}\text { Wire Feed } \\
\text { Rate } \\
(\mathrm{mm} / \mathrm{min})\end{array}$ & $\begin{array}{c}\text { Welding } \\
\text { Current } \\
\text { (amp) }\end{array}$ & $\begin{array}{c}\text { Experiment } \\
\text { al Value }\end{array}$ & ANN Value & $\begin{array}{l}\text { \% of } \\
\text { Error }\end{array}$ & $\begin{array}{c}\text { Experime } \\
\text { ntal } \\
\text { Value }\end{array}$ & $\begin{array}{l}\text { ANN } \\
\text { Value }\end{array}$ & $\begin{array}{c}\% \text { of } \\
\text { Error }\end{array}$ \\
\hline 1 & 0.8 & 4600 & 194 & 1.5000 & 1.5251 & -1.6733 & 20.0000 & 20.9130 & -4.5650 \\
\hline 3 & 0.8 & 4600 & 209 & 1.5000 & 1.5386 & -2.5733 & 25.0000 & 24.7171 & 1.1316 \\
\hline 5 & 0.8 & 4600 & 225 & 2.0000 & 1.9835 & 0.8250 & 25.0000 & 25.2629 & -1.0516 \\
\hline 7 & 0.8 & 4600 & 240 & 2.0000 & 2.0247 & -1.2350 & 20.0000 & 19.7470 & 1.2650 \\
\hline 9 & 0.8 & 4600 & 255 & 2.0000 & 2.0428 & -2.1400 & 15.0000 & 15.1108 & -0.7387 \\
\hline 11 & 0.8 & 5600 & 271 & 2.0000 & 2.0351 & -1.7550 & 20.0000 & 19.9796 & 0.1020 \\
\hline 13 & 0.8 & 5600 & 286 & 2.5000 & 2.5297 & -1.1880 & 20.0000 & 19.2199 & 3.9005 \\
\hline 15 & 0.8 & 5600 & 302 & 2.0000 & 2.0348 & -1.7400 & 20.0000 & 19.4382 & 2.8090 \\
\hline 17 & 0.8 & 5600 & 317 & 3.0000 & 2.9827 & 0.5767 & 15.0000 & 15.7019 & -4.6793 \\
\hline 19 & 0.8 & 5600 & 332 & 3.0000 & 3.0556 & -1.8533 & 15.0000 & 15.9533 & -6.3553 \\
\hline 21 & 1.0 & 4600 & 194 & 1.5000 & 1.5298 & -1.9867 & 20.0000 & 20.9353 & -4.6765 \\
\hline 23 & 1.0 & 4600 & 209 & 2.0000 & 1.9785 & 1.0750 & 20.0000 & 20.7426 & -3.7130 \\
\hline 25 & 1.0 & 4600 & 225 & 2.0000 & 1.9465 & 2.6750 & 20.0000 & 20.2920 & -1.4600 \\
\hline 27 & 1.0 & 4600 & 240 & 2.0000 & 2.0521 & -2.6050 & 20.0000 & 19.7789 & 1.1055 \\
\hline 29 & 1.0 & 4600 & 255 & 2.5000 & 2.5354 & -1.4160 & 20.0000 & 19.1451 & 4.2745 \\
\hline 31 & 1.0 & 5600 & 271 & 3.0000 & 2.9638 & 1.2067 & 15.0000 & 15.8096 & -5.3973 \\
\hline 33 & 1.0 & 5600 & 286 & 2.5000 & 2.5345 & -1.3800 & 20.0000 & 19.2533 & 3.7335 \\
\hline 35 & 1.0 & 5600 & 302 & 2.5000 & 2.4936 & 0.2560 & 20.0000 & 19.4737 & 2.6315 \\
\hline 37 & 1.0 & 5600 & 317 & 3.5000 & 3.5315 & -0.9000 & 20.0000 & 19.7385 & 1.3075 \\
\hline 39 & 1.0 & 5600 & 332 & 3.5000 & 3.4927 & 0.2086 & 15.0000 & 15.9898 & -6.5987 \\
\hline
\end{tabular}

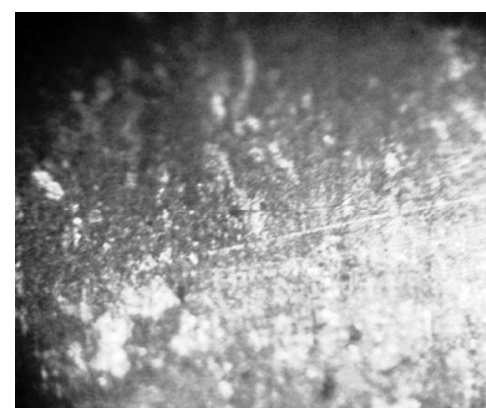

Figure 6. Microstructure of weldment for electrode wire diameter $0.8 \mathrm{~mm}$, wire feed rate $4600 \mathrm{~mm} / \mathrm{min}$ and current 232 amps.

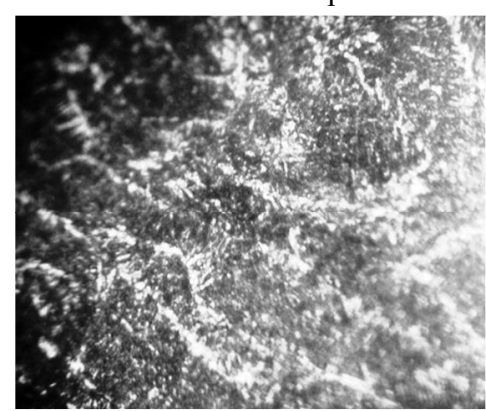

Figure 9. Microstructure of weldment for electrode wire diameter $1.0 \mathrm{~mm}$, wire feed rate $4600 \mathrm{~mm} / \mathrm{min}$ and current 232 amps.

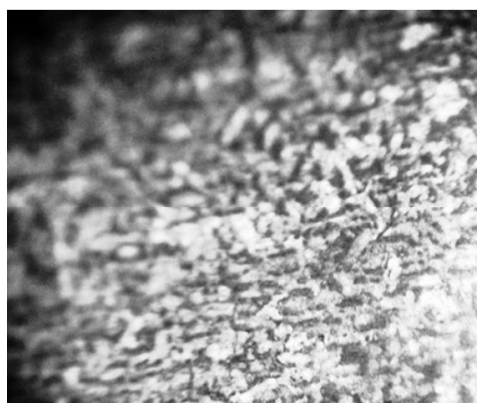

Figure 7. Microstructure of weldment for electrode wire diameter $0.8 \mathrm{~mm}$, wire feed rate $4600 \mathrm{~mm} / \mathrm{min}$ and current 240 amps.

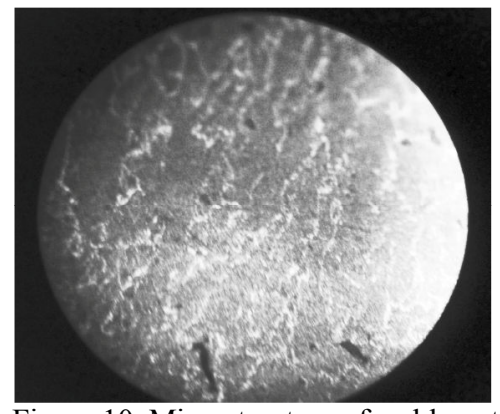

Figure 10. Microstructure of weldment for electrode wire diameter $1.0 \mathrm{~mm}$, wire feed rate $4600 \mathrm{~mm} / \mathrm{min}$ and current 240 amps.

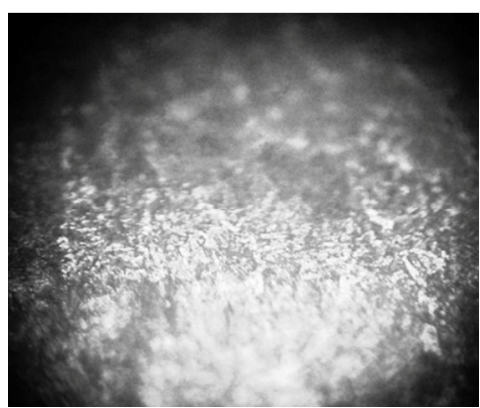

Figure 8. Microstructure of weldment for electrode wire diameter $0.8 \mathrm{~mm}$, wire feed rate $5600 \mathrm{~mm} / \mathrm{min}$ and current 317 amps.

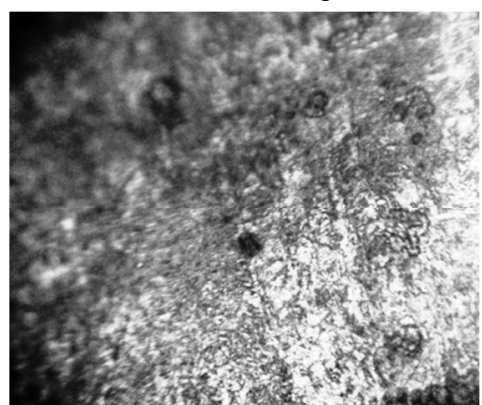

Figure 11. Microstructure of weldment for electrode wire diameter $1.0 \mathrm{~mm}$, wire feed rate $5600 \mathrm{~mm} / \mathrm{min}$ and current 317 amps. 
Figures 6 and 7 show the microstructure of weldment for electrode wire diameter $0.8 \mathrm{~mm}$, wire feed rate $4600 \mathrm{~mm} / \mathrm{min}$ and current 232 and 240 amps respectively. Figure 8 shows the same for electrode wire diameter $0.8 \mathrm{~mm}$, wire feed rate 5600 $\mathrm{mm} / \mathrm{min}$ and current 317 amps. Figures 9 and 10 show the microstructure of weldment for electrode wire diameter $1.0 \mathrm{~mm}$, wire feed rate $4600 \mathrm{~mm} / \mathrm{min}$ and current 232 and 240 amps respectively. Figure 11 shows the same for electrode wire diameter 1.0 $\mathrm{mm}$, wire feed rate $5600 \mathrm{~mm} / \mathrm{min}$ and current 317 amps.

\section{DISCUSSIONS}

Researchers have stated that arc spread increases almost linearly with the arc length and the area of the arc is more with larger diameter of the electrodes. Again it has been also stated that the increase in radius of the arc spread the depth of penetration decreases $^{4,5}$. It can be observed from Figs. 1 and 2 that the depth of heat affected zone increased with increasing current, wire feed rate as well as for increasing electrode wire diameter. Figures 1-4 show the depth of HAZ and hardness of weldment respectively. According to Table 1 and Figs. 1-4, in each for current range from 194 amps to 263 amps and from 271 amps to 340 amps electrode wire feed rate is $4600 \mathrm{~mm} / \mathrm{min}$ and $5600 \mathrm{~mm} / \mathrm{min}$ respectively. In Fig. 1 for current range 194 to 263 amps and for wire feed rate $4600 \mathrm{~mm} / \mathrm{min}$, the depth of HAZ started with $1.5 \mathrm{~mm}$ and rise up to $2.5 \mathrm{~mm}$. And for current range 271 to 340 amps and for wire feed rate $5600 \mathrm{~mm} / \mathrm{min}$, the depth of HAZ started with $2.0 \mathrm{~mm}$ and rise up to $3.0 \mathrm{~mm}$. In Fig. 2 the same type of phenomena is present. But in case of different wire diameter from Figs. 1 and 2, the depth of HAZ is larger for larger wire diameter. Again from Figs. 1 and 2 , it is quite clear that in all individual cases the experimental results and results through ANN are almost same; with percentage of error as $4.5 \%$ at maximum current range for sample no. 40. In Figs. 1 and 2, the depth of HAZ starts from $1.5 \mathrm{~mm}$ for both $0.8 \mathrm{~mm}$ and $1.0 \mathrm{~mm}$ diameter electrode wire; but with the increase in current the depth of HAZ increases and in case of larger wire diameter the values of the depth of HAZ is larger up to $3.5 \mathrm{~mm}$. Again, Fig. 1 compared with Fig. 2 shows that with the increase in wire feed rate from $4600 \mathrm{~mm} / \mathrm{min}$ to $5600 \mathrm{~mm} / \mathrm{min}$ and current range from 194-263 amps to 271-340 amps the values of the depth of HAZ increases gradually from $1.5 \mathrm{~mm}$ to $3.5 \mathrm{~mm}$.

From literature it has been observed that the penetration and HAZ are controlled by the rate of heat input, which is a function of current, arc length, arc travel rate and polarity. The depth of HAZ varies for different current ranges and electrode wire diameters. Again, it is stated that when the energy density is low the depth of heat affected zone increases $^{6}$. Same has been observed in Figs. 1 and 2 and also in Table 1.

As it is seen in literature, that weldment hardness mostly depends on cooling rate and medium of cooling if welding performed perfectly. If cooling rate is high, the hardness will be higher. If cooling medium is oil rather than water or air, the hardness will be higher ${ }^{6}$. By investigating the data in Table 1 and Figs. 3 and 4 , it is very much clear that the results obtained from experiment and ANN is closely matched. From Figs. 3 and 4, it can be observed that in the same current range 194-263 amps the hardness value started with 20 and more stable at larger wire diameter. But in the current range 271-340 amps the same phenomena are observed with some little deviation. Again, for the same electrode wire diameter and same wire feed rate the hardness decreases as the current increases with some little deviation. But in case of same wire feed rate and greater wire diameter, the hardness is lower most of the times. And in individual case the hardness is lowest at higher current range as shown in Figs. 3 and 4.

Figure 5 shows the microstructure of the base metal, revealing the presence of near equal amount of austenite and ferrite. The ferrite regions are seen as dark etched regions in the micrograph. The cooling rates associated with welding controls the solidification and subsequent solid state transformation in the mild steel weld regions, a distinctly different morphological microstructure is obtained in these welds when compare with base metal. The microstructure depicts the characteristics grain structure of weld metals, with austenite being manifested in the matrix of ferrite. The cooling rate associated with the gas metal arc welding is comparatively slow so the ferrite content in the weld metal is not so higher. As the weld was cooled slowly, sufficient time was available for the formation of a thick continuous grain boundary austenite. In spite of these from Figs. 6 and 7, it is obvious that the tendency of ferrite formation is higher with increasing current and as well as with larger electrode wire diameter, which is also depicts in Figs. 8 and 11. In the same electrode wire diameter and wire feed rate, grains are more fine with increasing current, which are clear in Figs. 6, 7, 9 and 10.

Again it could be noticed from the values in Table 1 that there is literally not much of variation in the weld zone hardness values despite the fact that there exists a different morphological microstructure features and variation in ferrite/austenite ratio. So ferrite and austenite do not show large differences. Therefore, the hardness values of the different weld metals do not vary significantly.

Figures 10 and 11 show the microstructure of the weld metal for certain welding parameters. The black circle represents the carbon nodule in the weld metal and the grain boundaries are also shown. In Fig. 7 
predominantly ferrite structure with small amount of austenite is present. Coarsening of the grains in the $\mathrm{HAZ}$ is due to the heating of these regions well above the transition temperature at which metal starts to transform to a new structure. The effect of composition plays an important role in controlling the ferrite-austenite ratio of mild steel weld metal. It is evident from the Fig. 7 the entire austenite in the weld metal seems to have been confined in to the grain boundary region. As it is seen in literature that ferrite or alpha iron is a solid solution of body centered cubic iron, it has a maximum solid solubility of $0.022 \%$ carbon at a temperature of $717^{\circ} \mathrm{C}$. And between $1394^{\circ} \mathrm{C}$ and $912^{\circ} \mathrm{C}$ iron undergoes a polymorphic transformation from the body centered cubic to face centered cubic structure, which is more commonly known as austenite. In fact it has been observed in the microstructures of some selected weldment samples that in the penetration zone and heat affected zone the austenite and ferrite structure respectively are clearly present.

The HAZ grain sizes of all samples were refined compared to that of the base metal. The base metal is characterized by a crystallized microstructure with equi-axed grains with relatively uniform grain size. A different grain size structure was formed in the weld region. The micro structure of the weld regions of weld metals was not easily discernible due to the difficulty in achieving a satisfactory etching contrast.

\section{CONCLUSIONS}

Based on the experimental work and the artificial neural network modeling work done, the following conclusions can be drawn from the above investigations:

- For every change in process parameters during the experiment a significant change in hardness occurred. In a particular current range the hardness is more stable and higher for relatively larger electrode wire diameter. And it is more viable in the lower current range of 194-263 amps. Again there has a little tendency to increase hardness for larger wire diameter and greater wire feed rate.
- The values of the depth of HAZ increases with the increasing current range as well as with the increase in electrode wire diameter and electrode wire feed rate.

- Microstructure of weldment and base metal are significantly different. In case of weldment there are more austenitic structure in penetration zone and ferrites structure in heat affected zone. With increasing current ferrite formation increases. Again with increasing current and wire diameter the grain structure is finer.

- Welding current, electrode wire diameter, electrode wire feed rate appear to be important process parameters in MIG welding, with their direct effects on hardness, the depth of HAZ and microstructure.

- Artificial neural networks based approach can be used effectively for predicting the depth of heat affected zone and hardness of weldments.

\section{REFERENCES}

1. Apps, R. L., and Lelson, K. A., 1963, Effect of welding variables upon bead shape and size in submerged arc welding. Weld. Met. Fabr. 31(11): 453-s to 457-s.

2. Gurev, H. S., and Stout, R. D. 1963. Solidification phenomena in inert gas metal arc welds. Weld. J. 42(97): 298 -s to 310 -s.

3. Molt, B. C. 1962. $\mathrm{CO}_{2}$ welding process. Weld Engineer. 47(6A): 5-s to 20-s.

4. Mahapatra, M. M., Ali, M. S., Datta, G. L., and Pradhan, B. 2005. Modeling and predicting the effects of process parameters on weldment characteristics in shielded metal arc welding. Indian Welding Journal. 38(2): 22-s to 29-s.

5. Jadavpur University. December 5-7. 2003. MetalArc weld penetration capability studies and analysis. Proc. of National Seminar on Weld Integrity. G. L. Datta, pp. 8-11.

6. Bradstreet, B. J. 1969. Effect of welding condition on cooling rate and hardness in the heat affected zone. Weld. J. 48(11): 499-s to 504-s. 